\title{
Universal primers for amplifying the complete coding sequence of cytoplasmic heat shock protein 90 (HSP90) in Lepidoptera
}

\author{
Peng Jun XU ${ }^{1,4, *}$, Tong LI ${ }^{1,4, *}$, Jin Hua XIAO ${ }^{1}$, Robert W. MURPHY ${ }^{3,5}$ and Da Wei HUANG ${ }^{1,2, * *}$ \\ ${ }^{1}$ Key Laboratory of Zoological Systematics and Evolution, Institute of Zoology, Chinese Academy of Sciences, \\ 1 Beichen West Road, Chaoyang District, Beijing 100101, China \\ ${ }^{2}$ College of Life Sciences, Hebei University, Baoding, 071002, China \\ ${ }^{3}$ State Key Laboratory of Genetic Resources and Evolution, Kunming Institute of Zoology, Chinese Academy of Sciences, \\ Kunming 650223, China \\ ${ }^{4}$ Graduate School of the Chinese Academy of Sciences, Beijing, China \\ ${ }^{5}$ Department of Natural History, Royal Ontario Museum, 100 Queen's Park, Toronto, Ontario M5S 2C6, Canada
}

Key words. Universal primer, Lepidoptera, coding sequence, untranslated region, HSP90, RACE

\begin{abstract}
Using sequence alignment, a conserved domain in the 3' untranslated region (UTR) of the cytoplasmic heat shock protein 90 (HSP90) of Lepidoptera was found. This region is highly variable in other insect groups. Furthermore, universal primers were designed to amplify the complete coding sequence (CDS) of HSP90 from total genomic DNA in Lepidoptera, avoiding the commonly used reverse transcription-polymerase chain reaction (RT-PCR) and 3', 5'-rapid amplification of cDNA ends (RACE) methods based on cDNA. These primers amplified a fragment of about $2.25 \mathrm{~kb}$ in the 11 species tested, which represent seven different families of Lepidoptera, including moths and butterflies. The results suggest that the conserved domain of 3'UTR is universal in Lepidoptera and these primers successfully amplify the complete CDS of cytoplasmic HSP90 from genomic DNA.
\end{abstract}

\section{INTRODUCTION}

Heat shock proteins 90 (HSPs90) are among the most abundantly expressed stress proteins and are recorded in all life stages. They play significant roles in the activation and regulation of numerous client proteins critical for diverse functions (Itoh et al., 1993; Izumoto \& Herbert, 1993; Gass et al., 1994; Rutherford \& Lindquist, 1998; Furay et al., 2006; Johnson \& Brown, 2009). Previous studies show that HSPs 90 are important in the development and adaptability of insects, for example, in morphogenesis (Rutherford \& Lindquist, 1998; Gunter \& Degnan, 2007) and resistance to pesticides (Skandrani et al., 2006; Eder et al., 2009). Moreover, HSPs 90 are used in systematic and population genetic studies of insects (Breglia et al., 2007; Fukuda \& Endoh, 2008; Feng et al., 2009).

For molecular studies of HSPs90 it is necessary to identify long stretches of DNA sequences as complete coding sequence (CDS) to draw conclusions. The complete CDS of HSP90 is commonly obtained using reverse transcription-polymerase chain reaction (RT-PCR) and 3', 5'-rapid amplification of cDNA ends (RACE) from cDNA templates (Sonoda et al., 2006; Li et al., 2009; Feng et al., 2010). Both these methods are difficult and costly.

Lepidopteran cytoplasmic $h s p 90$ is a single-copy gene without introns (Landais et al., 2001; Sonoda et al., 2006). After aligning existing sequences of cytoplasmic HSP90, a highly conserved region was located in the 3' untranslated region (UTR) in Lepidoptera, which is not present in the alignments of Diptera and Hymenoptera (data not shown).

Furthermore, a set of universal primers were designed for amplifying the gene that spanned the complete CDS and partial
3'UTR region. The primers successfully amplified specific cytoplasmic $h s p 90$ sequences from genomic DNA templates in all of the 11 species, representing seven lepidopteran families, tested.

\section{MATERIAL AND METHODS}

\section{Primer design}

The following $h s p 90$ sequences in the GenBank were used in the primer design: Bombyx mori (Linnaeus) (Bombycidae) (NM_001043411), Chilo suppressalis (Walker) (Crambidae) (AB206477), Plutella xylostella (Linnaeus) (Plutellidae) (AB214972), Spodoptera exigua (Hubner) (Noctuidae) (FJ524853), Omphisa fuscidentalis (Hampson) (Crambidae) (EF523380), Antheraea yamamai (Guerin-Meneville) (Saturniidae) (AB176669), and Mamestra brassicae (Linnaeus) (Noctuidae) (AB251894). The sequences were aligned using CLUSTAL $\mathrm{W}$ as implemented in MEGA 4.0 (Tamura et al., 2007) with default parameters.

\section{DNA extraction and primer evaluation}

Three individuals of each of 11 species from seven families of Lepidoptera, including both moths and butterflies, were used to evaluate the primers (Table 1). Genomic DNA was extracted from each individual using EasyPure Genomic DNA Extraction Kit (TransGen, Beijing, China), which purifies DNA using proteinase $\mathrm{K}$ digestion and silica-membrane technology.

\section{PCR amplifications, sequencing and sequence confirmation}

PCR reagents $(25 \mu \mathrm{l})$ contained $300 \mathrm{ng}$ of template DNA, 0.5 $\mu 1$ of each primer $(10 \mathrm{mM}), 3 \mu \mathrm{l}$ of dNTP mixture containing $2.5 \mathrm{mM}$ of each dNTP, $2.5 \mu 1$ of $10 \times$ reaction buffer and $1 \mathrm{U}$ of High Fidelity Expand Taq polymerase (TransGen). The PCR

\footnotetext{
* These authors contributed equally to the present study.
}

** Corresponding author; e-mail: huangdw@ioz.ac.cn 
TABLE 1. Lepidopteran species used to evaluate the universal primers and related information on their hsp90s.

\begin{tabular}{lcccccc}
\hline Family name & Species name & Species origin & Primers & AA & MW (kDa) & pI \\
\hline Noctuidae & Helicoverpa armigera & Laboratory rearing & L90F1/ L90R1 & 717 & 82.59 & 4.71 \\
& Helicoverpa assulta & Laboratory rearing & L90F1/ L90R1 & 717 & 82.19 & 4.85 \\
& $* *$ Mythimna separata & Wild & L90F1/ L90R1 & 717 & 82.56 & 4.71 \\
& Spodoptera litura & Wild & L90F1/ L90R1 & 717 & 82.60 & 4.73 \\
& $*$ Spodoptera exigua & Wild & L90F1/ L90R1 & 717 & 82.62 & 4.73 \\
Pyralidae & Ostrinia furnacalis & Wild & L90F1/ L90R1 & 716 & 82.41 & 4.75 \\
Geometridae & Exangerona prattiaria & Wild & L90F2/ L90R1 & 716 & 82.28 & 4.75 \\
Papilionidae & Papilio memnon & Wild & L90F1/ L90R1 & 717 & 82.44 & 4.74 \\
Plutellidae & *Plutella xylostella & Laboratory rearing & L90F1/ L90R1 & 717 & 82.37 & 4.70 \\
Nymphalidae & Argynnis paphia & Wild & L90F2/ L90R1 & 718 & 82.45 & 4.76 \\
Pieridae & Gonepteryx amintha & Wild & L90F2/ L90R1 & 718 & 82.56 & 4.68 \\
\hline
\end{tabular}

AA - the number of deduced amino acids; MW - molecular weight; $\mathrm{pI}$ - isoelectric point; * indicates that the former submission of the $h s p 90$ sequence to GenBank is the same as the sequence obtained in this study, which was not submitted; ** indicates that the former submission of the $h s p 90$ sequence to GenBank is different from the sequence obtained in this study, which was submitted.

reaction consisted of an initial denaturation step $\left(94^{\circ} \mathrm{C}\right.$ for 4 min) followed by 40 cycles of $94^{\circ} \mathrm{C}$ for $10 \mathrm{~s}, 50-52^{\circ} \mathrm{C}$ for 1 $\min , 68^{\circ} \mathrm{C}$ for $2.5 \mathrm{~min}$, and a final extension step $\left(72^{\circ} \mathrm{C}\right.$ for 10 min). Targeted PCR bands were purified and cloned using the pEASY-T3 Simple Cloning Vector (TransGen). Three positive clones of each insect were sequenced using a 3730XL sequencer based on the Sanger method (BioSune, Beijing, China). Nucleotide sequences were translated into amino acids to confirm translation and all sequences identified by BLAST searches implemented in National Center for Biotechnology Information (NCBI) (http://www. ncbi.nih.gov/BLAST/).

\section{RESULTS AND DISCUSSION}

\section{Primer design and evaluation}

A highly conserved region of aligned lepidopteran cytoplasmic $h s p 90$ sequences occurred in the 3' UTR (Fig. 1B). Furthermore, the following set of primers were designed: L90F1 (forward primer): 5'-AMAATGCCBGAAGRDATGC-3; L90F2 (forward primer): 5'-AMAATGCCBGAAGRDATGG-3; and L90R (reverse primer): 5'-GAACTAAATCAGTCTTTGG-3. Primer L90F1 or L90F2, located at the 5 ' end (Fig. 1A), contained the start codon and primer L90R1 was located in the 3' UTR region. Theoretically, these primers could amplify a 2.25 $\mathrm{kb}$ fragment that spans the complete CDS and part of the 3'UTR region of $h s p 90$.

The genomic DNA of Helicoverpa armigera was used as a reference to test for optimum PCR conditions. Because a fragment of approximately $2.25 \mathrm{~kb}$ was to be amplified, the cycling conditions were similar to those developed for Long-PCR (Cheng et al., 1994). The results of a range of annealing temperatures and different amounts of genomic DNA are summarized in Fig. 2A, B and the amplification condition detailed in the Material and Methods were chosen. PCR amplification of 33 genomic DNA samples of 11 species from seven families of the Lepidoptera were performed. Although some weak nonspecific amplifications occurred, the targeted fragments in 11 species were successfully amplified (Fig. 2C). A very weak band of the targeted fragment was observed in Gonepteryx amintha, probably because of poor PCR amplification efficiency. Nevertheless, the specific sequence was obtained after DNA purification, cloning, and sequencing.

\section{Identification of sequences}

Primers were designed and 11 sequences successfully obtained. Their characteristics (molecular weights, isoelectric points, and number of encoded amino acids) are presented in Table 1. BLAST searches were employed to confirm sequence

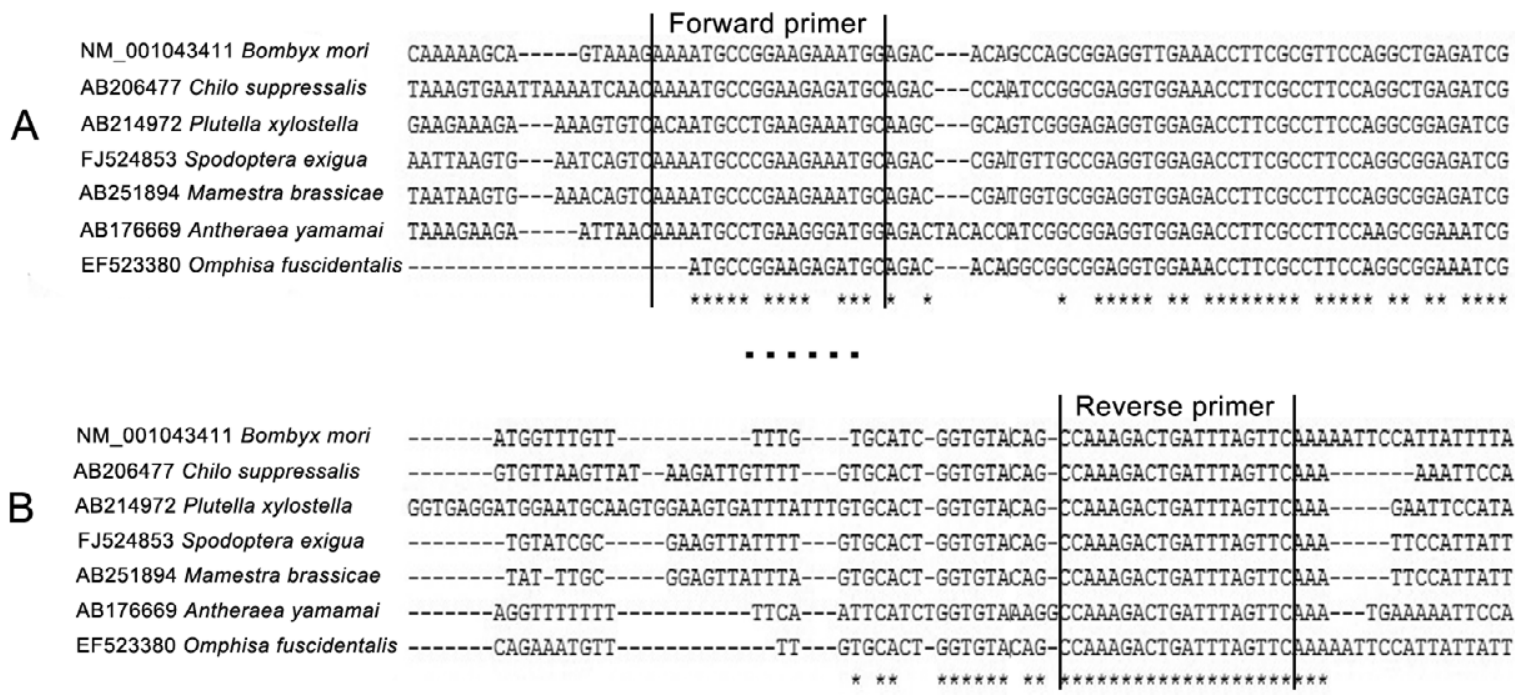

Fig. 1. The alignments of (A) the 5' end and (B) 3' UTR region of the heat shock protein 90 (HSP90) gene from Lepidoptera. Symbols: "-" represents a gap in the alignments, “*” identical sites in the alignments. 

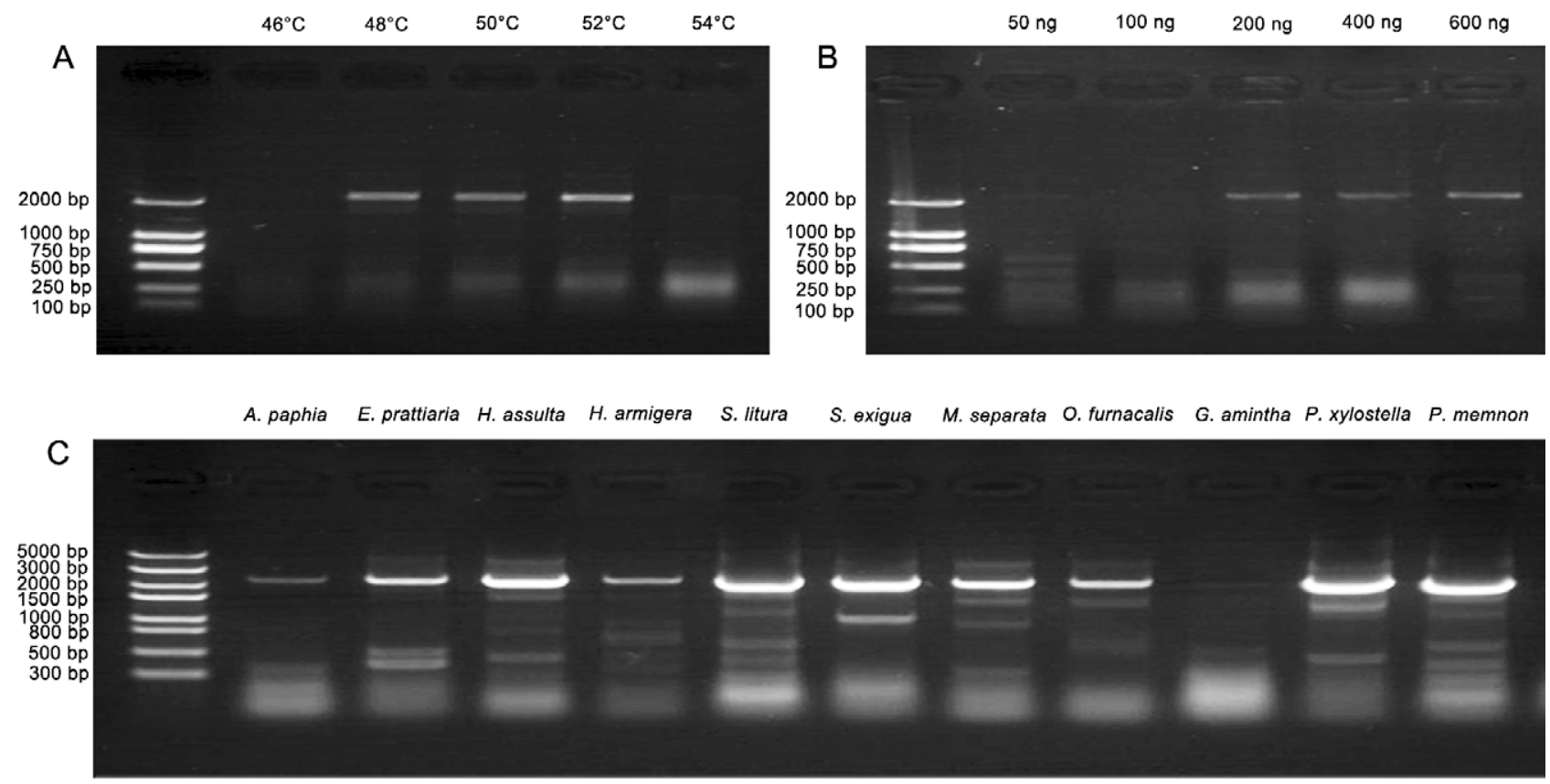

Fig. 2. Photographs of gels showing the effects of annealing temperatures and quantity of template DNA on the efficiency with which the $h s p 90$ sequence was amplified for 11 lepidopteran species. Analysis of the effect of (A) the different annealing temperatures and (B) the different amounts of DNA in H. armigera, and (C) the result of the amplification in the 11 species. Refer to Table 1 for generic names of species examined.

orthology. Both nucleotide and deduced amino acid sequences were tested. All sequences obtained with these primers were very similar to cytoplasmic $h s p 90$ of other lepidopteran species (Table 2). Moreover, the five conserved signatures of the HSP90 family (Gupta, 1995) and the conserved pentapeptide (MEEVD) of cytoplasmic HSP90 (Terasawa et al., 2005) were found in the alignments of the amino acid sequences (Fig. 3). The above analysis confirmed that the cytoplasmic $h s p 90$ sequences were amplified by these primers. The nucleotide sequences obtained in this study were deposited in GenBank under accession numbers GU230732-GU230740.

\section{Specificity of Lepidoptera $h s p 90$ gene and universal primers}

One intron is located directly upstream from the start codon of cytoplasmic $h s p 90$ in Diptera, Hymenoptera, and Coleoptera (Blackman \& Meselson, 1986; Benedict et al., 1996; KurzikDumke et al., 1996; Konstantopoulou \& Scouras, 1998). This intron regulates the basal transcription of the cytoplasmic $h s p 90$ at normal physiological temperatures (Lange et al., 1997). However, this intron is missing in the cytoplasmic hsp 90 of Lepidoptera (Landais et al., 2001; Sonoda et al., 2006).

In addition, the cytoplasmic $h s p 90$ of Lepidoptera has a conserved 3'UTR region, which is not present in at least two other

TABLE 2. Results of BLAST searches of $h s p 90$ sequences.

\begin{tabular}{|c|c|c|c|c|}
\hline Species & Closest species & Query coverage (\%) & E value* & Similarity $(\%)$ \\
\hline \multirow[t]{2}{*}{ Helicoverpa armigera } & Helicoverpa zea ${ }^{\mathrm{N}}$ & 100 & 0 & 98 \\
\hline & Helicoverpa zea ${ }^{\mathrm{P}}$ & 100 & 0 & 98 \\
\hline \multirow[t]{2}{*}{ Helicoverpa assulta } & Helicoverpa zea ${ }^{\mathrm{N}}$ & 95 & 0 & 97 \\
\hline & Helicoverpa zea ${ }^{\mathrm{P}}$ & 100 & 0 & 98 \\
\hline \multirow[t]{2}{*}{ Mythimna separata } & Mythimna separata & 95 & 0 & 97 \\
\hline & Mamestra brassicae & 100 & 0 & 98 \\
\hline \multirow[t]{2}{*}{ Spodoptera litura } & Spodoptera frugiperda $a^{\mathrm{N}}$ & 100 & 0 & 96 \\
\hline & Spodoptera frugiperda ${ }^{P}$ & 100 & 0 & 99 \\
\hline \multirow[t]{2}{*}{ Ostrinia furnacalis } & Loxostege sticticalis ${ }^{\mathrm{N}}$ & 94 & 0 & 90 \\
\hline & Chilo suppressalis $^{\mathrm{P}}$ & 100 & 0 & 97 \\
\hline \multirow[t]{2}{*}{ Exangerona prattiaria } & Spodoptera frugiperda ${ }^{\mathrm{N}}$ & 100 & 0 & 84 \\
\hline & Mamestra brassicae & 100 & 0 & 94 \\
\hline \multirow[t]{2}{*}{ Papilio memnon } & Spodoptera frugiperda $a^{\mathrm{N}}$ & 100 & 0 & 85 \\
\hline & Spodoptera frugiperda ${ }^{\mathrm{P}}$ & 100 & 0 & 94 \\
\hline \multirow[t]{2}{*}{ Argynnis paphia } & Spodoptera frugiperda & 100 & 0 & 85 \\
\hline & Spodoptera frugiperda ${ }^{\mathrm{P}}$ & 100 & 0 & 96 \\
\hline \multirow[t]{2}{*}{ Gonepteryx amintha } & Chilo suppressalis ${ }^{\mathrm{N}}$ & 95 & 0 & 83 \\
\hline & Bombyx mori ${ }^{\mathrm{P}}$ & 100 & 0 & 93 \\
\hline
\end{tabular}

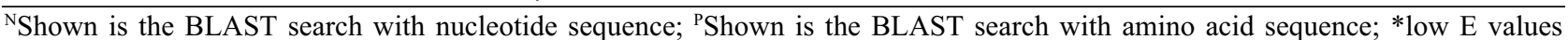
indicate high reliability of BLAST results. 
GU230732 Argynnis paphia GU230733 Papilio memnon GU230734 Ostrinia furnacalis GU230735 Spodoptera litura GU230736 Exangerona prattiaria GU230737 Mythimna separata GU230738 Gonepteryx amintha GU230739 Helicoverpa assulta GU230740 Helicoverpa armigera GU230732 Argynnis paphia GU230733 Papilio memnon GU230734 Ostrinia furnacalis GU230735 Spodoptera litura GU230736 Exangerona prattiaria GU230737 Mythimna separata GU230738 Gonepteryx amintha GU230739 Helicoverpa assulta GU230740 Helicoverpa armigera GU230732 Argynnis paphia GU230733 Papilio memnon GU230734 Ostrinia furnacalis GU230735 Spodoptera litura GU230736 Exangerona prattiaria GU230737 Mythimna separata GU230738 Gonepteryx amintha GU230739 Helicoverpa assulta GU230740 Helicoverpa armigera GU230732 Argynnis paphia GU230733 Papilio memnon GU230734 Ostrinia furnacalis GU230735 Spodoptera liture GU230736 Exangerona prattiaria GU230737 Mythimna separata GU230738 Gonepteryx amintha GU230739 Helicoverpa assulta GU230740 Helicoverpa armigera
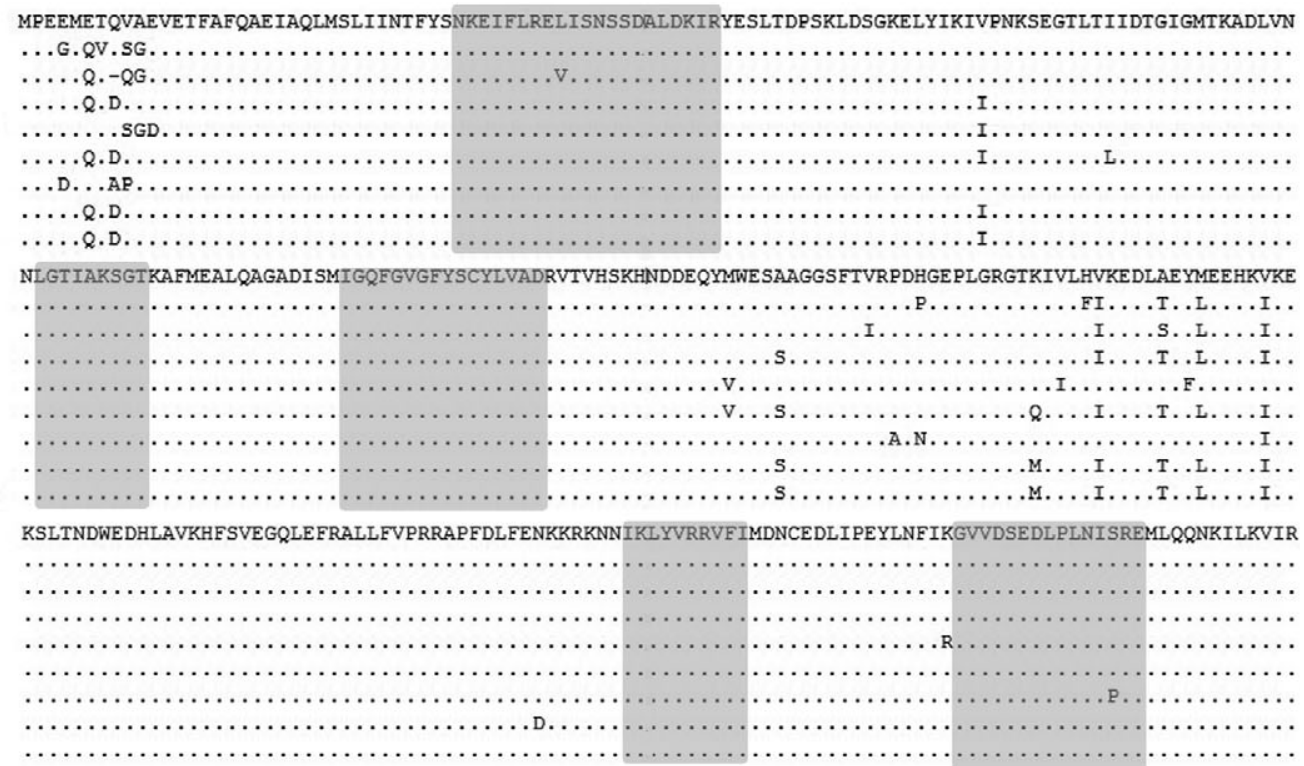
VPPLEGDADDASRMEEVD*

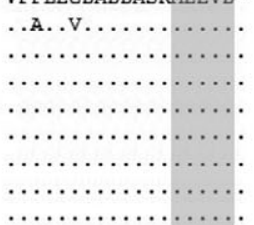

Fig. 3. Partial alignments of the amino acid sequences obtained in this study. The five conserved signatures of HSP90 family and the conserved pentapeptide of cytoplasmic HSP90 are shaded. Symbol "*” indicates the stop codon. GenBank accession numbers are given in left column.

insect orders. However, due to the limited information on the occurrence of cytoplasmic $h s p 90$ sequences in insects, it is not possible to confirm that this conserved 3'UTR region only occurs in Lepidoptera. Given this difference, this important functional marker could greatly facilitate research in Lepidoptera. The universal primers designed here amplified the complete CDS from genomic DNA, and, consequently, circumvented the use of costly RACE methods.

The amplification yielded some nonspecific bands, which might have resulted from the nonspecific binding of the primers. Nevertheless, identification and purification of the expected fragment for cloning and sequencing proved to be easy. Most of the products were amplified with primers L90F1/L90R and yielded the most consistent results during initial trials.

In conclusion, the results suggest that the cytoplasmic $h s p 90$ of Lepidoptera has a universally conserved 3'UTR region. The primers described here proved to be very promising for the amplification of the cytoplasmic $h s p 90$ fragment containing the complete CDS from Lepidoptera.

ACKNOWLEDGMENTS. This project was supported by the National Natural Science Foundation of China (NSFC grant no. 30770302, 30570970), partially by Program of Ministry of Science and Technology of the Republic of China (2006FY110500) and by National Science Fund for Fostering Talents in Basic Research (Special subjects in animal taxonomy, NSFCJ0630964/J0109). We would like to thank W. Xin and TransGen Biotech Company (Beijing) for providing reagents.

\section{REFERENCES}

Benedict M.Q., Levine B.J., Ke Z.X., Cockburn A.F. \& Seawright J.A. 1996: Precise limitation of concerted evolu- tion to ORFs in mosquito Hsp82 genes. Insect Mol. Biol. 5: 73-79.

Blackman R.K. \& Meselson M. 1986: Interspecific nucleotidesequence comparisons used to identify regulatory and structural features of the Drosophila Hsp82 gene. J. Mol. Biol. 188: 499-515.

Breglia S.A., Slamovits C.H. \& Leander B.S. 2007: Phylogeny of phagotrophic euglenids (Euglenozoa) as inferred from hsp90 gene sequences. J. Eukaryot. Microbiol. 54: 86-92.

Cheng S., Chang S.Y., Gravitt P. \& Respess R. 1994: Long PCR. Nature 369: 684-685.

Eder K.J., Leutenegger C.M., Kohler H.R. \& Werner I. 2009: Effects of neurotoxic insecticides on heat-shock proteins and cytokine transcription in Chinook salmon (Oncorhynchus tshawytscha). Ecotoxicol. Environ. Saf. 72: 182-190.

Feng H.Z., Wang L., Liu Y.H., He L., Li M., Lu W.C. \& Xue C.H. 2010: Molecular characterization and expression of a heat shock protein gene (HSP90) from the carmine spider mite, Tetranychus cinnabarinus (Boisduval). J. Insect Sci. 10: Art. 112.

Feng Y.Y., Dearen T., Cama V. \& Xiao L.H. 2009: 90kilodalton heat shock protein, Hsp90, as a target for genotyping Cryptosporidium spp. known to infect humans. Eukaryot. Cell 8: 478-482.

FUKUDA Y. \& ENDOH H. 2008: Phylogenetic analyses of the dinoflagellate Noctiluca scintillans based on beta-tubulin and Hsp90 genes. Eur. J. Protistol. 44: 27-33.

Furay A.R., Murphy E.K., Mattson M.P., Guo Z. \& Herman J.P. 2006: Region-specific regulation of glucocorticoid receptor/HSP90 expression and interaction in brain. J. Neurochem. 98: 1176-1184. 
Gass P., Schröder H., Prior P. \& Kiessling M. 1994: Constitutive expression of heat shock protein 90 (Hsp90) in neurons of the rat-brain. Neurosci. Lett. 182: 188-192.

Gunter H.M. \& Degnan B.M. 2007: Developmental expression of Hsp90, Hsp70 and HSF during morphogenesis in the vetigastropod Haliotis asinina. Dev. Genes Evol. 217: 603-612.

GuPTA R.S. 1995: Phylogenetic analysis of the $90 \mathrm{kD}$ heat shock family of protein sequences and an examination of the relationship among animals, plants, and fungi species. Mol. Biol. Evol. 12: 1063-1073.

IтоH H., Tashima Y., Eishi Y. \& OKeda R. 1993: Localization of Hsp90 in rat-brain. Int. J. Biochem. 25: 93-99.

IzUMoto S. \& Herbert J. 1993: Widespread constitutive expression of HSP90 messenger RNA in rat brain. J. Neurosci. Res. 35: $20-28$.

Johnson J.L. \& Brown C. 2009: Plasticity of the Hsp90 chaperone machine in divergent eukaryotic organisms. Cell Stress Chaper. 14: 83-94.

Konstantopoulou I. \& Scouras Z.G. 1998: The heat-shock gene hsp83 of Drosophila auraria: Genomic organization, nucleotide sequence, and long antiparallel coupled ORFs (LAC ORFs). J. Mol. Evol. 46: 334-343.

Kurzik-Dumke U., Neubauer M. \& Debes A. 1996: Identification of a novel Drosophila melanogaster heat-shock gene, lethal(2)denticleless [1(2)dtl], coding for an $83-\mathrm{kDa}$ protein. Gene 171: 163-170.

Landais I., Pommet J.M., Mita K., Nohata J., Gimenez S., Fournier P., Devauchelle G., Duonor-Cerutti M. \& Ogliastro M. 2001: Characterization of the cDNA encoding the $90 \mathrm{kDa}$ heat-shock protein in the Lepidoptera Bombyx mori and Spodoptera frugiperda. Gene 271: 223-231.

Lange P., Victor M. \& Benecke B.J. 1997: Basal level transcription of the human hsp86 gene is directed by intron-based elements. Genes Cells 2: 185-194.

Li P., Zha L., Zhang Z.H., Huang H., Sun H.Y., Song D.X. \& Zноч K.Y. 2009: Molecular cloning, mRNA expression, and characterization of HSP90 gene from Chinese mitten crab Eriocheir japonica sinensis. Comp. Biochem. Physiol. (B) 153: 229-235.

RUTHERFORD S.L. \& LindQuist S. 1998: Hsp90 as a capacitor for morphological evolution. Nature 396: 336-342.

Skandrani D., Gaubin Y., Vincent C., Beau B., Murat J.C., Soleilhavoup J.P. \& Croute F. 2006: Relationship between toxicity of selected insecticides and expression of stress proteins (HSP, GRP) in cultured human cells: Effects of commercial formulations versus pure active molecules. Biochim. Biophys. Acta 1760: 95-103.

Sonoda S., Ashfaq M. \& Tsumuki H. 2006: Cloning and nucleotide sequencing of three heat shock protein genes (hsp90, hsc70, and hsp19.5) from the diamondback moth, Plutella xylostella (L.) and their expression in relation to developmental stage and temperature. Arch. Insect Biochem. Physiol. 62: 80-90.

Tamura K., Dudley J., Nei M. \& Kumar S. 2007: MEGA4: Molecular Evolutionary Genetics Analysis (MEGA) software version 4.0. Mol. Biol. Evol. 24: 1596-1599.

Terasawa K., Minami M. \& Minami Y. 2005: Constantly updated knowledge of Hsp90. J. Biochem. 137: 443-447.

Received August 19, 2010; revised and accepted October 8, 2010 